\title{
Proton and Calcium-Gated lonic Mesochannels: Phosphate-Bearing Polymer Brushes Hosted in Mesoporous Thin Films As Biomimetic Interfacial Architectures
}

\author{
Annette Brunsen, ${ }^{\dagger}$ Carolina Díaz, ${ }^{\ddagger}$ Lía I. Pietrasanta, ${ }^{\ddagger, \perp}$ Basit Yameen, ${ }^{\S}$ Marcelo Ceolín, $, 1, \perp$ \\ Galo J. A. A. Soler-Illia, ${ }^{* \dagger, \perp}$ and Omar Azzaroni $*, \|, \perp$ \\ ${ }^{\dagger}$ Gerencia Química, Comisión Nacional de Energía Atómica (CNEA), Argentina \\ ${ }^{\ddagger}$ Centro de Microscopías Avanzadas, Facultad de Ciencias Exactas y Naturales, Universidad de Buenos Aires, Argentina \\ ${ }^{\S}$ Max-Planck-Institut für Polymerforschung, Mainz, Germany \\ "Instituto de Investigaciones Fisicoquímicas Teóricas y Aplicadas (INIFTA), Departamento de Química, Facultad de Ciencias \\ Exactas, Universidad Nacional de La Plata, CONICET, Argentina \\ ${ }^{\perp}$ Consejo Nacional de Investigaciones Científicas y Técnicas (CONICET), C1033AAJ Buenos Aires, Argentina
}

Supporting Information

\begin{abstract}
Rational construction of interfaces based on multicomponent responsive systems in which molecular transport is mediated by structures of nanoscale dimensions has become a very fertile research area in biomimetic supramolecular chemistry. Herein, we describe the creation of hybrid mesostructured interfaces with reversible gate-like transport properties that can be controlled by chemical inputs, such as protons or calcium ions. This was accomplished by taking advantage of the surface-initiated polymerization of 2-(methacryloyloxy)ethyl phosphate (MEP) monomer units into and onto mesoporous silica thin films. In this way, phosphate-bearing polymer brushes were used as "gatekeepers" located not only on the outer surface of mesoporous thin films but also in the inner environment of the porous scaffold.

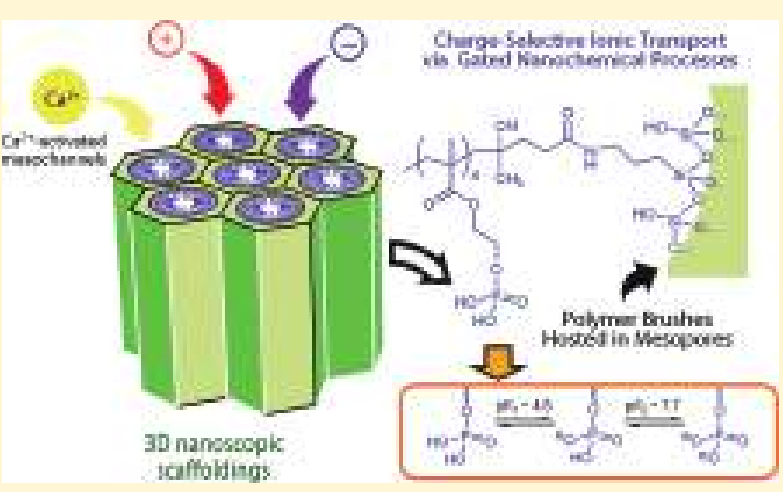
Pore-confined PMEP brushes respond to the external triggering chemical signals not only by altering their physicochemical properties but also by switching the transport properties of the mesoporous film. The ion-gate response/operation was based on the protonation and/or chelation of phosphate monomer units in which the polymer brush works as an off-on switch in response to the presence of protons or $\mathrm{Ca}^{2+}$ ions. The hybrid meso-architectured interface and their functional features were studied by a combination of experimental techniques including ellipso-porosimetry, cyclic voltammetry, X-ray reflectivity, grazing incidence small-angle X-ray scattering, X-ray photoelectron spectroscopy, and in situ atomic force microscopy. In this context, we believe that the integration of stimuli-responsive polymer brushes into nanoscopic supramolecular architectures would provide new routes toward multifunctional biomimetic nanosystems displaying transport properties similar to those encountered in biological ligand-gated ion channels.
\end{abstract}

\section{INTRODUCTION}

The design, synthesis, and operation of functional interfaces with switchable properties controlled by chemical inputs constitute a fascinating challenge in the fields of materials science and nanotechnology. ${ }^{1}$ For instance, the generation of interfaces discriminating the transport of cationic and anionic species, i.e., permselectivity, is an intrinsic mechanism of nature, as can be observed in human skin or cornea, which exploit fixed charges in the membrane to generate differential permeabilities. $^{2}$

The idea to create nanostructured hybrid systems that can function in a similar way as biological ion channels and pores has been around for many years. ${ }^{3}$ This quest for new platforms enabling the selective transport of ionic species stems from the wide variety of technological applications relying on "gated" transport processes, such as ultrafiltration, controlled delivery, ${ }^{4}$ or even proton-gated devices based on aligned tubular mesoporous silica. ${ }^{5}$ In this regard, ion channels exhibit two very attractive features, that is, selective ion conduction, and the ability to gate-open in response to the presence or the absence of certain chemical species, which in turn leads to the formation of a conduction pathway (or pore) through which ions diffuse across the membrane. ${ }^{6}$ So far, most explanations of this phenomenon have been based on the notion that "conducting"

Received: September 29, 2011

Revised: January 14, 2012

Published: February 7, 2012 
and "non-conducting" states represent "open" and "closed" configurations of the channel, and that the transition between them results from physicochemical changes in the channel environment. ${ }^{7}$ For example, in the case of ligand-activated ion channel gating, a ligand binds to receptor domains in the channel, inducing conformational changes that lead to opening of the ion conduction pore.

In this context, hybrid polymer-inorganic mesoporous thin films result in particularly attractive platforms to translate biologically inspired concepts into the design of practical materials and "active" nanosystems. ${ }^{8}$ In biological ion channels, organization on the nanometer scale is crucial for attaining remarkable properties and functional capabilities. The highly sophisticated functions found in ion channels originate from their elaborate structures. ${ }^{9,10}$ Rather than consisting of monolithic architectures, these structures are spatially organized assemblies of different specific functions in which the harmony of noncovalent and covalent interactions leads to adjustable functions. With the correct choice of building blocks and selfassembly conditions, it is possible to produce nanostructured materials via sol-gel processes with precisely defined and tunable chemical functions incorporated into ordered mesostructured frameworks. ${ }^{11}$ Then, the incorporation of polymer brushes ${ }^{12}$ into the mesopores enables a better control over the density of functional groups incorporated in the pores as well as endows the mesoporous scaffold with built-in responses to a myriad of chemical stimuli. ${ }^{13}$ As a result, the modification of the inner and outer environment of mesostructured materials with macromolecular units introduces a particularly interesting strategy to enhance active functions. ${ }^{4}$ Recently, MartínezMáñez and co-workers ${ }^{15}$ reported the first gated hybrid mesostructured system operating in aqueous solution and controlled ionically by $\mathrm{pH}$ modulation. This approach was based on the outer surface modification of mesoporous silica scaffolds with polyamines in order to create dual $\mathrm{pH}$ - and anion driven gate-like ensembles. In similar ways, several authors started to explore the use of polyelectrolytes to manipulate molecular transport through mesoporous materials. For example, the infiltration of polyelectrolytes into mesoporous silica has been extensively explored by Caruso and collaborators and subsequently exploited to build up mesoporous polymerbased spheres for delivery purposes. ${ }^{16}$

An ongoing challenge in materials science relies on the construction of fully synthetic hybrid assemblies displaying gating and charge selectivity properties resembling those observed in biological ion channels. Interesting examples are proton-gated acid-sensing ion channels (ASICs) in peripherical sensory neurons and in the neurons of the central nervous system. These are cation-selective, biological channels that act as gateable ionic filters enabling the selective passage of cations only under determined $\mathrm{pH}$ conditions and play an important role in a variety of physiological processes such as nociception, mechanosensation, and synaptic plasticity. On the other hand, calcium plays a central role in the regulation of diverse cellular processes including membrane ion permeability, and signal transduction. As such, the relevance of calcium-activated ion channels ( $\mathrm{CaCCs})$ is decisive in cellular physiology, including epithelial secretion of electrolytes and water, sensory transduction, regulation of neuronal and cardiac excitability, and regulation of vascular tone.

Within this framework, the functioning of ligand-gated ion channels such as ASICs and CaCCs propose challenging new ideas in molecular materials science: designing ionic meso- channels in hybrid interfacial assemblies displaying charge selectivity with built-in proton- and calcium-activated gating properties. Being able to design multicomponent mesoarchitectures at interfaces with functions similar to ligand-gated ion channels would be of great importance for further expanding the scope of applications of these nanomaterials.

In this work, we describe the creation of mesostructured polymer-inorganic assemblies displaying $\mathrm{H}^{+}$and $\mathrm{Ca}^{2+}$-dependent ionic transport properties. The designed nanogated architecture involves the use of phosphate-bearing polymer brushes ${ }^{17}$ hosted in mesoporous silica thin films as functional hybrid ensembles capable of discriminating and modulating the transport of cations and anions over a wide $\mathrm{pH}$ range (see Figure $S 1$ in the Supporting Information file for further details). Furthermore, the binding and release of calcium ions leads to the opening/closing of the gate and therefore controls the conduction of ions through the mesochannels. In close resemblance to ligand-gated channels in biology, the ligand induces the opening of the nanochannels and switches the "non-conducting" interfacial mesostructure to a "conducting" state.

\section{EXPERIMENTAL SECTION}

Synthesis of Mesoporous Amino-Silica Thin Films. Propylamino-functionalized mesoporous thin films were synthesized via the co-condensation of the oxide precursor tetraethoxysilane (TEOS, Merck) and the amine precursor 3-aminopropyltriethoxysilane (APTES, Fluka 98\%) in the presence of the template (F127 block copolymer, Aldrich, $\left.M_{\mathrm{w}}=13600\right)$. The precursor solution was prepared using 0.8 TEOS/0.2 APTES/0.005 F127/24 EtOH/5.2 $\mathrm{H}_{2} \mathrm{O} / 0.28 \mathrm{HCl}$. This solution was used to produce films by dipcoating on silicon, glass, and ITO substrates under $40-50 \%$ relative humidity conditions at $25{ }^{\circ} \mathrm{C}\left(1-2 \mathrm{~mm} \mathrm{~s}^{-1}\right.$ withdrawing speed). The organic template was removed by extraction in $0.01 \mathrm{~mol} \mathrm{dm}^{-3} \mathrm{HCl}$ in absolute ethanol (Merck) for 3 days under stirring.

Anchoring 4,4'-Azobis(4-cyanopentanoic acid) on Mesoporous Amino-Silica Films. 4,40-Azobis(4-cyanopentanoic acid) (0.5 g, $1.78 \mathrm{mmol})$ and $0.92 \mathrm{~g}(4.5 \mathrm{mmol})$ of $N, N^{\prime}$-dicyclohexylcarbodiimide (DCC) were added to a single-neck Schlenk flask and closed with a rubber septum. The reactants were degassed under vacuum for 15 min followed by backfilling with $\mathrm{N}_{2}(\mathrm{~g})$. Forty milliliters of dry dimethylformamide (DMF) were added to the flask through the septum with the help of a syringe, and the reactants were allowed to dissolve. After complete dissolution, $0.13 \mathrm{~mL}$ of dry pyridine was added. Mesoporous samples were sealed in Schlenk tubes and degassed ( $4 \times$ high-vacuum pump $/ \mathrm{N}_{2}$ refill cycles). Then, the reaction mixture was syringed into the Schlenk flasks containing the aminomodified films and left overnight under $\mathrm{N}_{2}(\mathrm{~g})$ at room temperature. Finally, the mesoporous substrates were removed from the reaction mixture and immersed in a beaker containing DMF. The beaker was gently shaken over a period of $2 \mathrm{~h}$. The modified substrates were then washed twice with DMF followed by washing with water and ethanol. The initiator-functionalized mesoporous films were stored under nitrogen below $4{ }^{\circ} \mathrm{C}$ until further use.

Poly(methacryloyl ethylene phosphate) (PMEP) Brush Growth on Initiator-Functionalized Mesoporous Silica Films. In a $50 \mathrm{~mL}$ Schlenk flask, $5.5 \mathrm{~g}$ of the 2-(methacryloyloxy)ethyl phosphate (MEP) (purchased from Sigma-Aldrich) was dissolved in $200 \mathrm{~mL}$ of tetrahydrofuran (THF). The solution was degassed by $\mathrm{N}_{2}(\mathrm{~g})$ bubbling for $1 \mathrm{~h}$. The initiator functionalized mesoporous thin films were sealed in a Schlenk tube and degassed $(4 \times$ high vacuum pump $/ \mathrm{N}_{2}$ refill cycles). The monomer solution was syringed into this Schlenk flask adding enough to wholly immerse the mesoporous substrate. The flask was immersed in an oil bath preheated to $65{ }^{\circ} \mathrm{C}$. The polymerization was carried out at $65^{\circ} \mathrm{C}$ for $1 \mathrm{~h}$. The substrates were then removed from the polymerization solution and rinsed with THF. 
Characterization. SAXS-2D, GISAXS, and XRR. Film mesostructure was analyzed by small-angle $X$-ray scattering with twodimensional detection (SAXS-2D) at the D11A-SAXS2 beamline at the Laboratório Nacional de Luz Síncrotron, Campinas, SP, Brazil (LNLS), using $\lambda=1.608 \AA$, a sample-detector distance of $650 \mathrm{~mm}$, and a CCD detector ( $3^{\circ}$ incidence). X-ray reflectivity (XRR) and grazing-incidence small-angle X-ray scattering (GISAXS) measurements were performed at the D10A-XRD2 beamline of LNLS $(\lambda=1.608 \AA)$. In order to obtain accurate density values, measurements were performed under low-humidity conditions (under a stream of dry nitrogen). This is a relevant experimental aspect, as the condensation of atmospheric moisture within the pores could lead to a severe underestimation of the film mesoporosity.

$X$-ray Photoelectron Spectroscopy (XPS). XPS experiments were performed at the SXS beamline of the Laboratorio Nacional de Luz Síncrotron, Campinas, SP, Brazil (LNLS) using $1840 \mathrm{eV}$ incident photon energy. The beamline was equipped with a PHOIBOS HSA 3500 (Specs) hemispherical electron analyzer. In order to estimate the degree of polymerization of the brushes grown inside the mesoporous film, i.e., the number of repeating units in a grafted polymer chain, we proceeded to a quantitative analysis of the XP spectra. The quantification was based on the XPS signal intensity comparison between the $\mathrm{N} 1 \mathrm{~s}$ and $\mathrm{P} 2 \mathrm{~s}$ signals, which correspond to the amide (grafting site) and the phosphate groups (monomer units), respectively. As is well-known, the XPS peak area is directly proportional to the concentration of an element, but the factor of proportionality depends on several variables such as photoionization cross section (intrinsic of each element) and instrumental corrections. To simplify the analysis, $\left(\mathrm{NH}_{4}\right)_{2} \mathrm{HPO}_{4}$ salt was used as a reference sample. This solid compound contains both elements, $\mathrm{N}$ and $\mathrm{P}$, in a well-known stoichiometry, 2N:1P. From the reference XPS measurements (under exactly the same experimental conditions as those used in the brush-modified mesopororus films), it was possible to obtain the required calibration factor, $\alpha$, for the analysis of both elements $(\mathrm{N}$ and $P)$ in our experimental setup.

Environmental Ellipsometric Porosimetry. Water adsorption curves (at $298 \mathrm{~K}$ ) were measured by environmental ellipsometric porosimetry (EEP, SOPRA GES5A). Film thickness and refractive index values were obtained from the ellipsometric parameters $\psi$ and $\Delta$ under nitrogen flux containing variable water vapor quantities; $P / P_{\text {sat }}$ was varied from 0 to $1\left(P_{\text {sat }}\right.$ being the saturation water vapor at $\left.298 \mathrm{~K}\right)$. Film pore volume and pore size distribution at each $P / P_{\text {sat }}$ were obtained by modeling the refractive index obtained according to a three-medium Bruggeman effective medium approximation (BEMA). Pore size distributions were obtained from the analysis of the refractive index variation, using the WinElli 2 software (SOPRA, Inc.).

Electrochemical Measurements. Cyclic voltammetry (CV) was used to analyze the change in the transport properties of electrochemical probes, anionic $\mathrm{Fe}(\mathrm{CN})_{6}{ }^{3-}$ and cationic $\mathrm{Ru}\left(\mathrm{NH}_{3}\right)_{6}{ }^{3+}$, under different environmental conditions. As recently revisited by Walcarius, ${ }^{18}$ changes in the voltammetric response of mesoporous electrodes reflect the changes in probe concentration or diffusion in response to external stimuli or the architecture of the pore. To this end, mesoporous films modified with phosphate-bearing polymer brushes were prepared on bare ITO electrodes. In most cases, environmental changes promote immediate response in electrochemical readout; however, diffusional voltammetric currents reach their maximum after a period of $2-3 \mathrm{~h}$. We hypothesize that this phenomenon could be ascribed to slow conformational changes of the nanoconfined polymer brushes and as well as gradual solvation changes in the pore environment.

Atomic Force Microscopy (AFM) Imaging. Tapping-mode AFM in liquid was performed using a Nanoscope IIIa-Quadrex MultimodeAFM (Digital Instruments-Veeco Metrology, Santa Barbara, CA) with a vertical $\mathrm{J}$ scanner having a maximal lateral range of approximately $150 \mu \mathrm{m}$. Standard silicon nitride cantilevers with a nominal spring constant of $0.12 \mathrm{~N} \mathrm{~m}^{1-}$ and a nominal tip radius of $20 \mathrm{~nm}$ were exposed to UV-ozone for 5 min before mounting in the AFM liquid cell. Cantilever spring constants calibration were performed with a custom written Matlab routine (The Mathworks, Inc.) applying the thermal noise method. ${ }^{19}$ After a period of $15-30$ min of thermal relaxation, initial engagement of the tip was achieved at scan size zero to minimize sample deformation and tip contamination. The substrates were rinsed with Milli-Q water and dried under a gentle stream of nitrogen. Experiments were done in different solutions of 0.1 $\mathrm{M} \mathrm{KCl}\left(\mathrm{pH} \mathrm{3,8}\right.$, and $\left.2 \mathrm{mM} \mathrm{Ca}{ }^{2+}\right)$. Samples were allowed to equilibrate for $30 \mathrm{~min}$ before performing experiments. The images $(512 \times 512$ pixels $)$ were captured with a scan size of between 0.5 and 1 $\mu \mathrm{m}$ at a scan rate of $1-2$ scan lines per second. Images were processed by flattening using NanoScope software to remove background slope.

Data Analysis of the Force Curves. Forces were calculated by multiplying the cantilever deflection by the cantilever spring constant $(0.0951 \mathrm{~N} / \mathrm{m})$ according to Hooke's law. Tip-sample separations were obtained by subtracting the change in tip deflection from the measured relative sample position according to the method of Ducker et al. ${ }^{20}$ Tipically, a total of 30 curves $(512 \times 512$ points $)$ were collected at $1 \mathrm{~Hz}$ and $300 \mathrm{~nm} \mathrm{Z}$ scan size.

\section{RESULTS AND DISCUSSION}

Building up the Hybrid Polymer-Inorganic Interfacial Assembly. We used amino-functionalized mesoporous silica films $\left(\mathrm{R}-\mathrm{NH}_{2}: \mathrm{Si} 0.2: 1\right)$ as a platform to build up the hybrid polymer-inorganic interfacial assembly. Films were produced by dip-coating on silicon, glass, or indium tin oxide (ITO) substrates using Pluronics F127 block copolymer as the structure-directing agent. ${ }^{21}$ Films exposed to successive consolidation and extraction process displayed pore arrays as determined by scanning electron microscopy (SEM) imaging (Figure 1a). AFM imaging corroborated that consolidated and extracted mesoporous thin films are very smooth with rootmean-square roughness (rms) of ca. $0.26 \mathrm{~nm}$ (see Figure S2 in the Supporting Information file). Films undergo an uniaxial contraction perpendicular to the substrate (45\% thickness reduction) after a consolidation thermal treatment at $200{ }^{\circ} \mathrm{C}$ (during $24 \mathrm{~h}$ ) followed by template extraction, thus leading to pores with an ellipsoidal shape. Pore volume and pore size can be calculated from the water sorption isotherms (Figure 2a) obtained from ellipsometric porosimetry measurements following the model proposed by Boissiére et al. ${ }^{22}$ for ellipsoidal mesopores. For the amino-silica samples, a pore volume of $32 \%$, an average major pore diameter of $\sim 8 \mathrm{~nm}$ (calculated from the isotherm adsorption branch), and an average neck size (from the desorption branch) of $\sim 3 \mathrm{~nm}$ were estimated (Figure $2 \mathrm{~b})$. The mesoporous film thickness was $\sim 52 \mathrm{~nm}$ as determined by XRR; GISAXS indicated that mesopore arrays with local order and an interpore distance of $\sim 12 \mathrm{~nm}$ were obtained (Figure $1 \mathrm{~b}, \mathrm{c}$ ). This mesophase resulted in a highly accessible mesoporous framework with cage-like pores, as deduced from the isotherm shape (Type IV with $\mathrm{H} 2$ hysteresis loops). ${ }^{23}$

The amino groups on the pore surface were used as grafting sites for the surface-initiated polymerization of the polyprotic monomer MEP (see Figure S1 in the Supporting Information file). Briefly, the amino groups were initially conjugated to 4,4'azobis(4-cyanopentanoic acid), which acted as the surfaceconfined polymerization initiator. Subsequently, brush growth was accomplished by surface-initiated radical polymerization of the MEP monomers in the presence of the adequate solvent during a preset reaction time (see Experimental Section for details). This process led to the surface modification of the mesoporous film with covalently anchored PMEP brushes. Adsorption-desorption isotherms of the polymer-modified samples (Figure 2a) also reveal Type IV features with $\mathrm{H} 2$ loops 

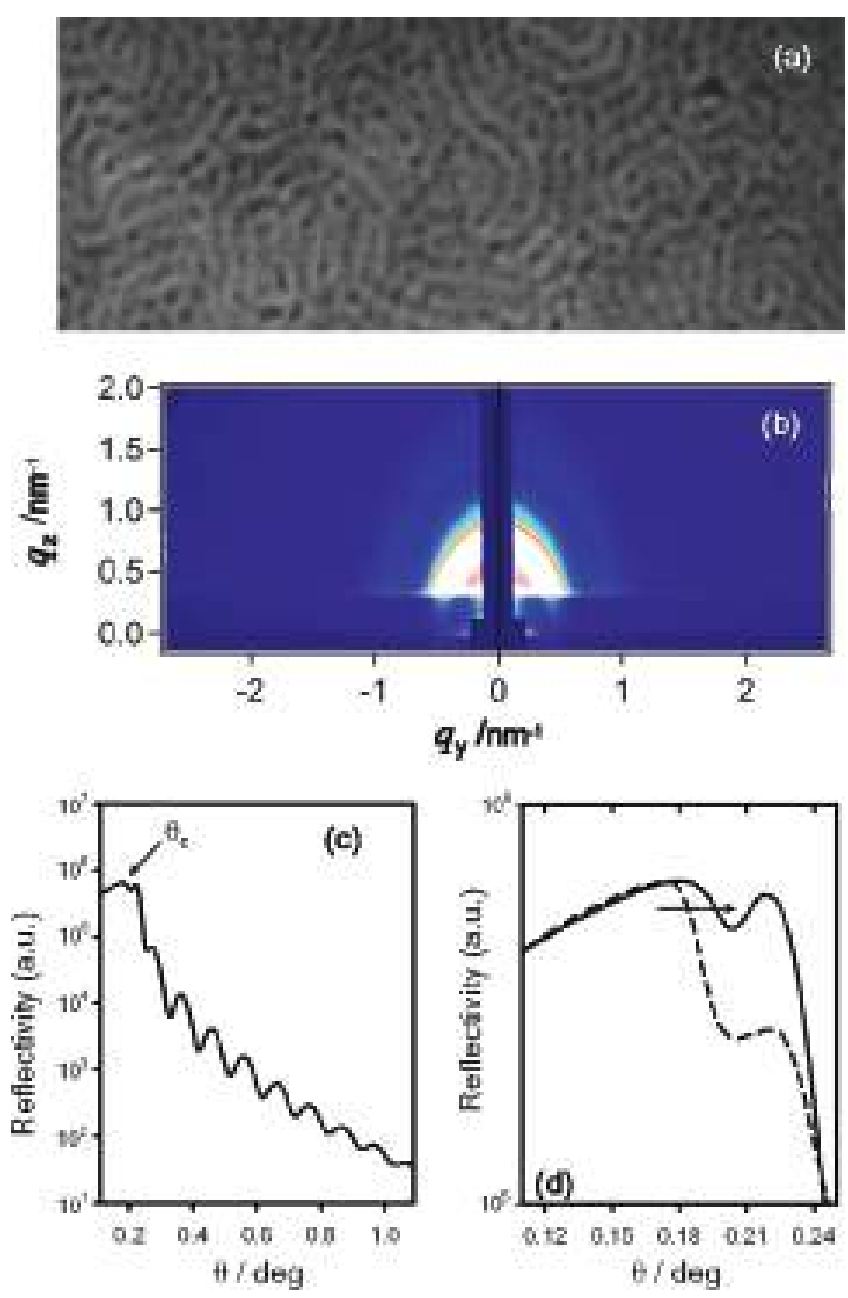

Figure 1. (a) Scanning electron micrograph of PMEP-modified mesoporous thin films and (b) GISAXS patterns of aminofunctionalized mesoporous thin films. (c) XRR data corresponding to the PMEP-modified mesoporous silica films. The critical angle, $\theta_{\mathfrak{c}}$, is indicated. (d) Magnification of the reflectivity data in the angular region close to the critical angle for the mesoporous silica film prior to (dotted trace) and after (solid trace) surface-initiated polymerization of MEP brushes. The arrow indicates the shift in the critical angle.

(caged pores with restrictions). A comparison of the isotherms corresponding to empty and filled pores reveal that pore volume decreases from 32 to $22 \%$ upon PMEP functionalization. Thereafter, ellipso-porosimetry was performed to study the effect of PMEP brush growth on the pore size distribution of the mesoporous films (Figure $2 b$ ). The pore and interpore neck size distributions before and after PMEP modification were extracted from the adsorption and desorption curves, respectively. ${ }^{24}$ Figure 2 shows that pore and neck diameters are reduced from 7.8 and 3.2 to 4.7 and $1.8 \mathrm{~nm}$, respectively, upon the mesoporous structure being modified by the polyeletrolyte brush. The narrowing of $3.1 \mathrm{~nm}$ in the pore diameter and 1.4 $\mathrm{nm}$ in the neck dimension is a strong indication that surfaceinitiated polymerization of MEP took place in the inner environment of the mesoporous film.

Thereafter, the surface chemical composition of the mesoporous films was monitored by XPS. It is worth mentioning that under our experimental conditions XPS probes the film surface, pore openings, and film walls up to a thickness of $\sim 9 \mathrm{~nm}$, which is nearly the depth corresponding to two pore layers. XPS characterization of mesoporous films indicated the appearance of an intense peak at $189.2 \mathrm{eV}$ (typical binding energy of $\mathrm{P} 2 \mathrm{~s}$ photoelectrons) corroborating the presence of phosphate groups in the samples after the polymerization (see Figure S3 in the Supporting Information file). From the XPS signal we estimated a degree of polymerization $(n)$ equal to $7 \pm 2$ monomer units per grafted chain. The protocol to estimate $n$ from XPS measurements has been described in detail in previous publications. ${ }^{25}$

XRR also revealed changes in film electronic density due to the polymerization process occurring in the film. XRR measurements were performed under dry nitrogen flow that ensured $0 \%$ humidity conditions in order to avoid artifacts due to water adsorption and/or condensation on the pore surface. After the polymerization reaction, an increase in the critical angle, $\theta_{\mathcal{O}}$ was observed (Figure 1d), which correlates with an increase in density ${ }^{26}$ and a mesopore filling fraction of $23 \%{ }^{27}$ The filling fraction was estimated following the experimental protocols described by Gibaud and co-workers. ${ }^{28}$ This XRR data further demonstrate the presence of polymer brushes inside the pores and not only on the surface of the film.

pH-Gated Polymer Brush-Inorganic Mesoporous Channels. In biological channels, the mechanisms for activating the transport of ions can be triggered by changes in the local concentration of protons that ultimately switch the ionic transport from an "off" state, in which no or low ionic current passes through the channels, to an "on" state that is evidenced by a high transmembrane ionic current. For example, the tetrameric M2 protein from influenza A, one of the simplest $\mathrm{pH}$-gated ion channels known, suffers a conformational switch upon protonation of its histidine residues. ${ }^{29}$ The structural switch, from a uniprotonated to a biprotonated channel, causes an electrostatic repulsion between the charged histidine moieties that pushes the helices apart. More important, the $\mathrm{pH}$ required to activate the channel is close to the $\mathrm{p} K_{\mathrm{a}}$ of the histidine groups, indicating that the protonation change is responsible for the channel gating. ${ }^{30}$ This example illustrates how relevant mesopore responsiveness is in terms of adaptability to environmental changes and tunability of electrostatic characteristics by chemical stimuli.

To investigate the ionic transport properties of the hybrid interfacial assemblies, the diffusion of charged species through mesoporous films supported on ITO was electrochemically probed by $\mathrm{CV}$ using anionic and cationic electroactive probes, $\mathrm{Fe}\left(\mathrm{CN}_{6}\right)^{3-}$ and $\mathrm{Ru}\left(\mathrm{NH}_{3}\right)_{6}{ }^{3+}$, respectively. ${ }^{31}$ Part of the chemical richness of polyprotic MEP brushes lies in the fact that the equilibrium of the monomer units involves a variety of charged states ${ }^{32}$ that are thermodynamically controlled by the environmental $\mathrm{pH}$ value. ${ }^{33}$ So, proton concentration acts as an accurate chemical parameter responsible for setting different electrostatic conditions in the pore. As is well-known, the emergence of permselectivity effects or ionic gating requires the presence of surface charges on the mesopore walls. At $\mathrm{pH}<$ $\mathrm{p} K_{1}$ the dominant species in the brush are fully protonated MEP units $\left(\mathrm{MEPH}_{2}\right)$. We infer that at low $\mathrm{pH}$ values $(\mathrm{pH}<$ $\mathrm{p} K_{1}$ ) the interaction between protonated phosphate groups and surface silanols is governed by hydrogen bonding interactions. ${ }^{34}$ Hence, the mesoporous framework displays no surface charges, and, consequently, no permselectivity is observed in the corresponding cyclic voltammograms.

Figure 3 comparatively displays the cyclic voltammograms of ITO-supported PMEP-modified mesoporous silica thin films in the presence of $1 \mathrm{mM} \mathrm{Fe}\left(\mathrm{CN}_{6}\right)^{3-}$ (red trace, Figure 3a) and 

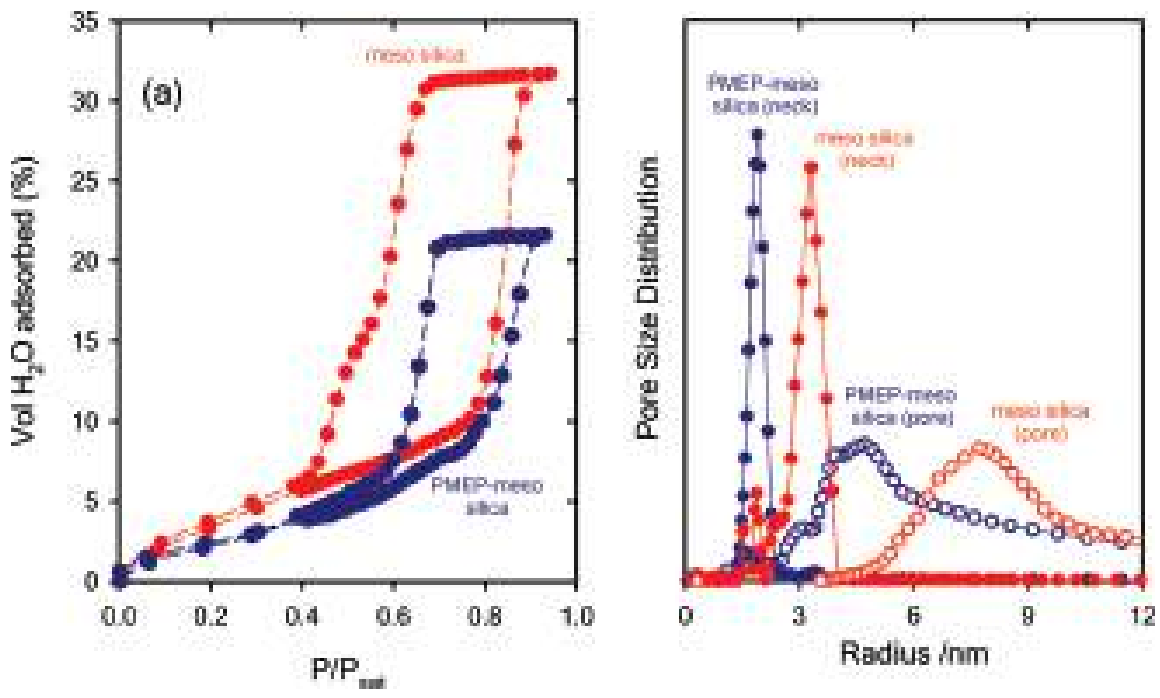

Figure 2. (a) Adsorption-desorption isotherms obtained by the EEP of unmodified and PMEP-modified mesoporous silica films. (b) Pore size distribution of unmodified mesoporous silica films and PMEP-modified mesoporous silica films, as determined by ellipso-porosimetry.

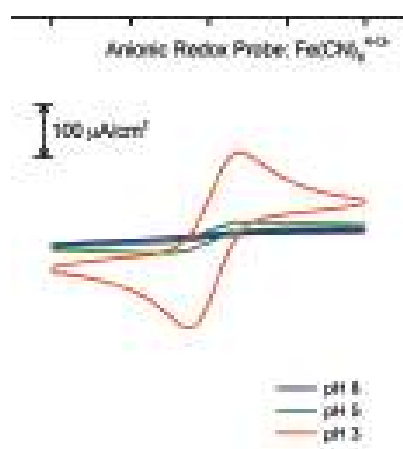

(a)

\begin{tabular}{|c|c|c|c|c|}
\hline-0.2 & 0.9 & 02 & 9.4 & OB \\
\hline
\end{tabular}

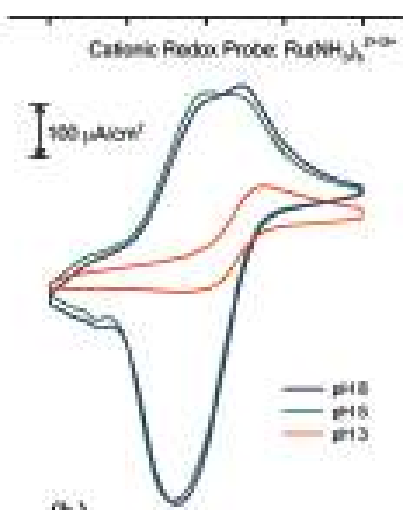

(b)

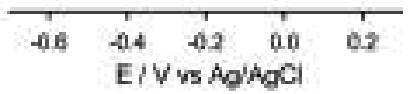

Figure 3. Comparative cyclic voltammograms displaying the molecular transport through PMEP-modified mesoporous thin films as a function of $\mathrm{pH}$ using (a) $\mathrm{Fe}(\mathrm{CN})_{6}{ }^{3-}$ as an anionic redox probe and (b) $\mathrm{Ru}(\mathrm{NH} 3)_{6}{ }^{3+}$ as a cationic redox probe. Scan rate: $200 \mathrm{mV} / \mathrm{s}$. Electrolyte: $1 \mathrm{mM}$ redox probe $+0.1 \mathrm{M} \mathrm{KCl}$ under different $\mathrm{pH}$ conditions: $\mathrm{pH} 8, \mathrm{pH} 5$, and $\mathrm{pH} 3$.

$\mathrm{Ru}\left(\mathrm{NH}_{3}\right)_{6}{ }^{3+}$ (red trace, Figure $3 \mathrm{~b}$ ) at $\mathrm{pH} 3$ by employing $0.1 \mathrm{M}$ $\mathrm{KCl}$ as the supporting electrolyte. In both cases, a well-defined electrochemical signal is observed with anodic currents of 156 and $127 \mu \mathrm{A} / \mathrm{cm}^{2}$ for $\mathrm{Fe}\left(\mathrm{CN}_{6}\right)^{3-}$ and $\mathrm{Ru}\left(\mathrm{NH}_{3}\right)_{6}{ }^{3+}$, respectively. The electrochemical data reveals that the fully protonated pore behaves as an open gate enabling the free diffusion of anionic and cationic species through the film. When $\mathrm{pH}$ is changed from 3 to 5 , the population of "monovalent" charged units $\left(\mathrm{MEPH}^{-}\right)$grows at the expense of the neutral species $\left(\mathrm{MEPH}_{2}\right)$, thus giving origin to a charged permselective pore (Figure 3). Changes in the voltammetric response of mesoporous electrodes reflect the changes in probe concentration or diffusion due to the architecture or electrostatic environment of the pores. We observed that increasing $\mathrm{pH}$ slightly above $\mathrm{p} K_{1}(4.5)$ has a significant effect on the transport properties of the mesoporous film. The electrochemical current of $\mathrm{Fe}\left(\mathrm{CN}_{6}\right)^{3-}$ decreased from 156 to $19 \mu \mathrm{A} / \mathrm{cm}^{2}$, whereas the current of $\mathrm{Ru}\left(\mathrm{NH}_{3}\right)_{6}{ }^{3+}$ increased from 127 to $283 \mu \mathrm{A} / \mathrm{cm}^{2}$. The generation of $\mathrm{MEPH}^{-}$units in the mesoporous films enhanced the voltammetric signal of $\mathrm{Ru}\left(\mathrm{NH}_{3}\right)_{6}{ }^{3+}$ ions dissolved in the electrolyte solution. Hence, increasing $\mathrm{pH}$ from 3 to 5 increased the ratio of electrochemical currents ${ }^{35}$ of cationic $\left(I_{\mathrm{Ru}}\right)$ and anionic $\left(I_{\mathrm{Fe}}\right)$ redox probes from 0.8 to 14.9 as a result of the

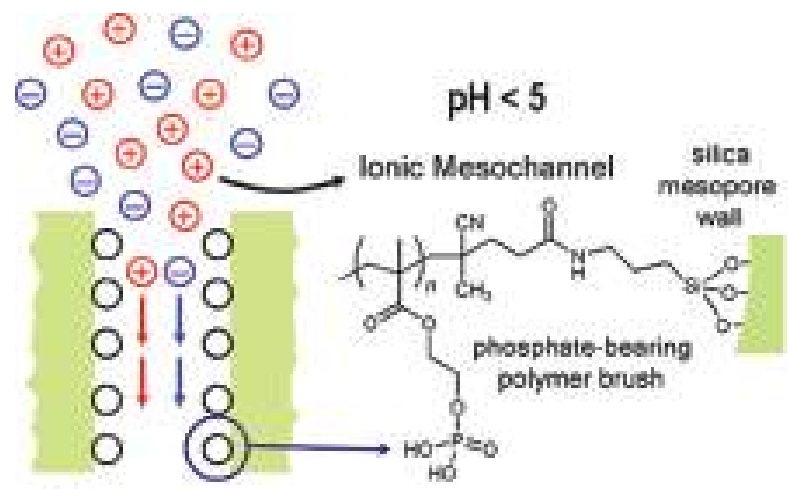

(a)

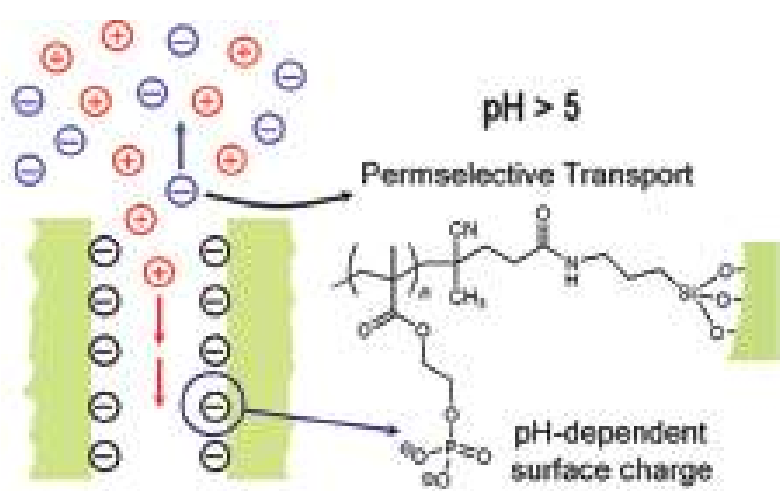

(b)

Figure 4. Schematic depiction of the ionic transport processes taking place in the hybrid polymer-inorganic interfacial assembly at different pH's: (a) $\mathrm{pH}<5$, ionic mesochannel (no exclusion of ionic species); (b) $\mathrm{pH}>5$, permselectiv transport of cations. 

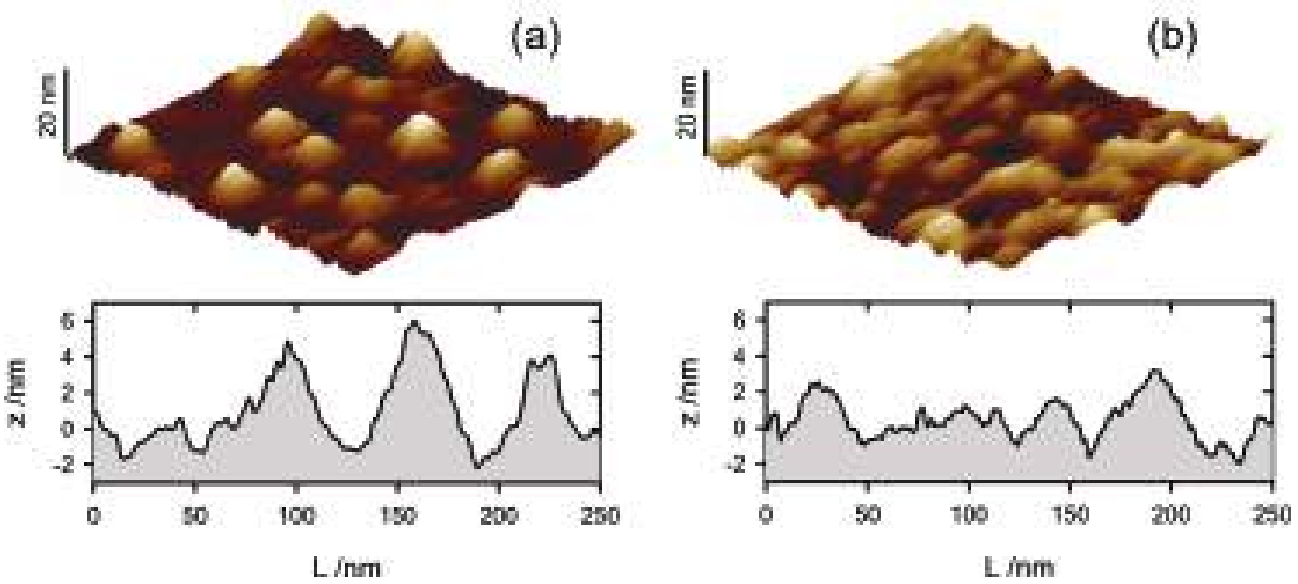

Figure 5. In situ AFM three-dimensional topography images and respective cross sections of MEP-modified mesoporous thin film in $0.1 \mathrm{M} \mathrm{KCl}$ solution at (a) $\mathrm{pH} 3$ and (b) $\mathrm{pH} 8$ (tapping mode; maximum $z$-scale: $20 \mathrm{~nm}$; scan size: $250 \mathrm{~nm} \times 250 \mathrm{~nm}$ ).

combination of permselective exclusion of anionic probes and preconcentration of cationic probes (Figure 4).

As expected, further increasing $\mathrm{pH}$ above $\mathrm{pK}_{2}$ (7.7) evidenced a more pronounced gating response of the interfacial assembly due to PMEP brushes are fully deprotonated $\left(\mathrm{MEP}^{2-}\right)$ and reach the maximum surface charge density in the pore. At $\mathrm{pH} \mathrm{8}$, a well-defined electrochemical response of $\mathrm{Ru}\left(\mathrm{NH}_{3}\right)_{6}{ }^{3+}$ ions was observed $\left(I_{\mathrm{Ru}} \sim 305 \mu \mathrm{A} / \mathrm{cm}^{2}\right)$, whereas similar experiments performed in the presence of $\mathrm{Fe}\left(\mathrm{CN}_{6}\right)^{3-}$ revealed that the electron transfer at the underlying ITO interface was strongly hindered $\left(I_{\mathrm{Fe}} \sim 5 \mu \mathrm{A} / \mathrm{cm}^{2}\right)$. This can be ascribed to the fact that the fully charged anionic MEP units completely exclude the anionic probes from the inner surroundings of the inorganic film. As an outcome of the interplay between preconcentration and exclusion effects, the $I_{\mathrm{Ru}} / I_{\mathrm{Fe}}$ parameter resulted in $\sim 61$, thus revealing that the $\mathrm{pH}$ induced generation of charges in the mesopores plays a critical role in the modulation of the gating properties.

AFM imaging of the outer MEP-modified mesoporous surface also indicated changes upon switching $\mathrm{pH}$ from 3 to 8 (Figure 5). It is worth mentioning that, due to the mesoporous films processing conditions, grafting sites are distributed not only on the pore walls but also on the outer surface of mesostructured film. Hence, upon polymerization a thin brush layer (thickness ca. $5 \mathrm{~nm}$ ) is also grown atop the ITO-supported mesoporous layer. AFM imaging at $\mathrm{pH} 3$ revealed the appearance of nanoaggregates on the outer mesoporous surface. According to recent theoretical work by Tagliazucchi et al. ${ }^{36}$ this observation can be ascribed to the formation of micelle-like nanodomains of collapsed PMEP in the fully protonated state. Then, upon ionization at $\mathrm{pH} 8$, thin PMEP brushes grafted on the outer region of the mesoporous film are fully extended due to electrostatic repulsion between like-charged monomers. This conformational reorganization was further supported by force-distance plots that reveal changes in the approach AFM curves (see Figure S4 in the Supporting Information file for further details).

The combined analysis of ionic transport through the mesochannels and the structural changes of the polymer layer on the outer surface of the mesoporous film suggests an interesting interplay between "inner" and "outer" chemistries in the hybrid interfacial architecture. At $\mathrm{pH} 8$, brushes display an extended conformation, and the strongly charged building blocks in the outer and inner environment of the mesopore drastically hinder the diffusion of anionic probes across the 52 $\mathrm{nm}$ thick hybrid film but, on the contrary, facilitates the preconcentration of $\mathrm{Ru}\left(\mathrm{NH}_{3}\right)_{6}{ }^{3+}$ ions. Decreasing the $\mathrm{pH}$ level to 3 leads to the PMEP brush collapse; however, the collapsed conformation of the thin polymer layer located atop the mesoporous film does not block the entrance of the mesopore, as corroborated by $\mathrm{CV}$ experiments. In this context, we hypothesize that anionic and cationic probes are able to diffuse through the outer collapsed polymer layer and shuttle across the mesoporous framework.

$\mathrm{Ca}^{2+}$-Gated Mesostructured Interfacial Assemblies. As is well-known in biological systems, or even in their man-made analogues, the interaction with calcium ions may trigger a broad variety of biophysicochemical processes even if its concentration is low compared to other ionic species in the same environment. ${ }^{37}$ Upon the stimulation by alkaline-earth ions, lipid layers undergo surface reorganization forming microscopic lipid channels displaying gating properties. ${ }^{38}$ The permeability transition pore (PTP) of the inner mitochondrial membrane provides another interesting example. This ion channel switches from low to high ionic conductance states depending on the saturation of the internal $\mathrm{Ca}^{2+}$-binding sites of the PTP. ${ }^{39}$ In most cases, direct gating of ion channels by $\mathrm{Ca}^{2+}$ is presumed to operate via interaction of the ions with $\mathrm{Ca}^{2+}$-binding motifs located in the channel protein. For example, the activation of $\mathrm{Ca}^{2+}$-gated ion channels in Xenopus oocytes and rat parotid gland has been modeled assuming that two or three $\mathrm{Ca}^{2+}$ ions interact with closed states of the channel protein in a linear sequence. Once $\mathrm{Ca}^{2+}$ ions are bound, the channel reaches the open state. ${ }^{40}$

With this in mind, we explored the gating properties of the PMEP in the presence of $\mathrm{Ca}^{2+}$ ions. Calcium is a very efficient phosphate binder ${ }^{41,42}$ that is experiencing a renewed interest as a chemical trigger in diverse biomimetic nanosystems. ${ }^{43,44}$ Recently, Börner et al. reported the use of $\mathrm{Ca}^{2+}$ ions for reversibly controlling the function of a peptide aggregator domain in peptide-polymer conjugates. ${ }^{45} \mathrm{Ca}^{2+}$-controlled transitions in peptide secondary structure may trigger selfassembly or disassembly of fibrillar peptide-polymer nanostructures or even controlling coil-to-helix in peptide-polymer conjugates. $^{46}$

To examine the effect of $\mathrm{Ca}^{2+}$ ions on the gating properties of PMEP-modified mesoporous thin films, we performed $\mathrm{CV}$ experiments with anionic $\mathrm{Fe}\left(\mathrm{CN}_{6}\right)^{3-}$ probes in the absence and 


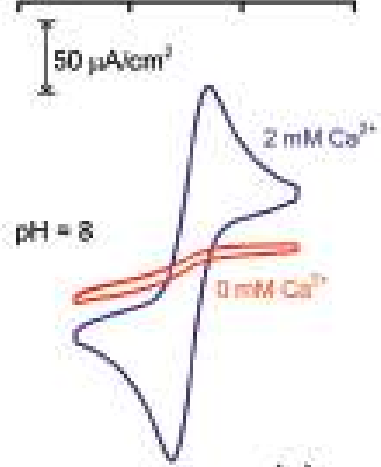

(a)

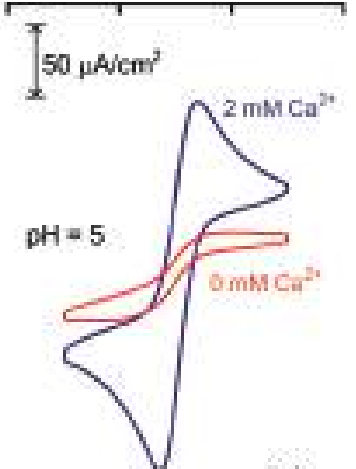

(b)

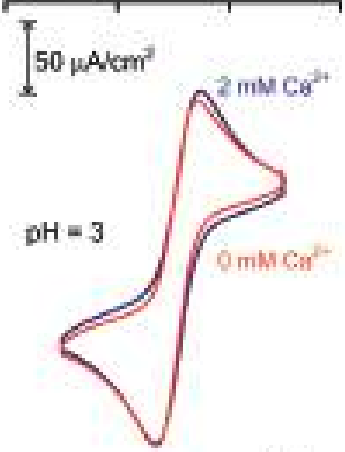

(c)

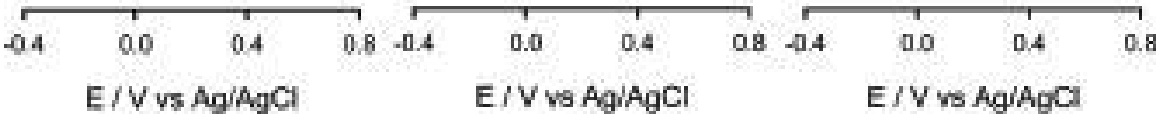

Figure 6. $\mathrm{CV}$ studies of molecular transport through PMEP-modified mesoporous thin films in the absence and in the presence of $\mathrm{Ca}^{2+}(2 \mathrm{mM}$ $\left.\mathrm{CaCl}_{2}\right)$ using $\mathrm{Fe}(\mathrm{CN})_{6}{ }^{3-}$ as a redox probe. Scan rate: $200 \mathrm{mV} / \mathrm{s}$. Electrolyte: $1 \mathrm{mM}$ redox probe $+0.1 \mathrm{M} \mathrm{KCl}$ under different $\mathrm{pH}$ conditions: $(\mathrm{a}) \mathrm{pH}$ 8 , (b) $\mathrm{pH} \mathrm{5,} \mathrm{(c)} \mathrm{pH} 3$.

in the presence of $2 \mathrm{mM} \mathrm{Ca}^{2+}$ using $0.1 \mathrm{M} \mathrm{KCl}$ as the supporting electrolyte. Figures 6 and 7 display the voltammo-

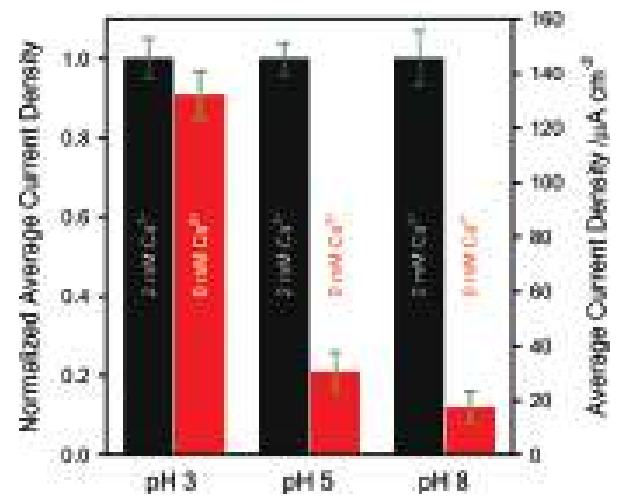

Figure 7. Histograms showing (normalized and average) variations in electrochemical current densities arising from the influence of $\mathrm{pH}$ and the presence of $\mathrm{Ca}^{2+}$ ions on the molecular transport of $\mathrm{Fe}(\mathrm{CN})_{6}^{3-}$ redox probes through the PMEP-modified mesopores.

grams and histograms that reflect the ionic transport properties of the interfacial architecture and their relative changes, respectively, under different $\mathrm{pH}$ conditions. At $\mathrm{pH} 8$ in the absence of $\mathrm{Ca}^{2+}$ ions the PMEP-modified mesopores are highly permselective and the passage of anionic probes is completely inhibited (Figure 8a). Then, the presence of $2 \mathrm{mM} \mathrm{Ca}^{2+}$ promoted drastic changes in the permselective properties of the mesoporous structure. The complexation of the divalent $\mathrm{MEP}^{2-}$ units with $\mathrm{Ca}^{2+}$ ions led to the "calcification" or neutralization of the charged groups in the mesoporous walls (Figure $8 \mathrm{~b}$ ), which in turn triggered the passage of anionic probes as revealed by the well-defined electrochemical signal corresponding to the $\mathrm{Fe}\left(\mathrm{CN}_{6}\right)^{3-}$ probes (Figure 6a). At $\mathrm{pH} 5$, a similar trend is observed but changes are less dramatic than in $\mathrm{pH} 8$ conditions due to the lower surface charge (Figure 7). However, the voltammograms show that the presence of $\mathrm{Ca}^{2+}$ leads to the opening of the mesochannel gate decorated with phosphate charged units and the subsequent transport of anionic probes. Lowering $\mathrm{pH}$ below $\mathrm{p} K_{1}(\mathrm{pH} 3)$ evidenced no changes between electrolyte solutions containing or not containing calcium ions (Figure 6a-c). At pH 3, MEP units are fully protonated, and the interfacial assembly is insensitive to the presence of $\mathrm{Ca}^{2+}$ because phosphate chelation is not favorable under those $\mathrm{pH}$ conditions.

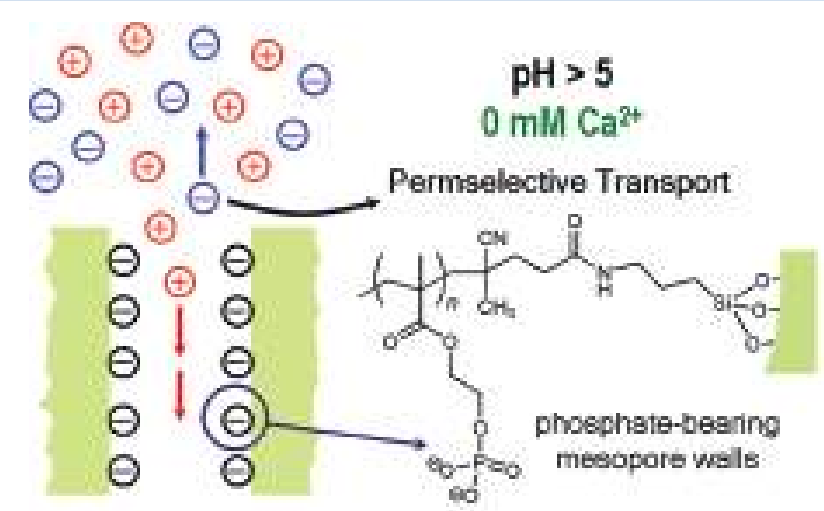

(a)

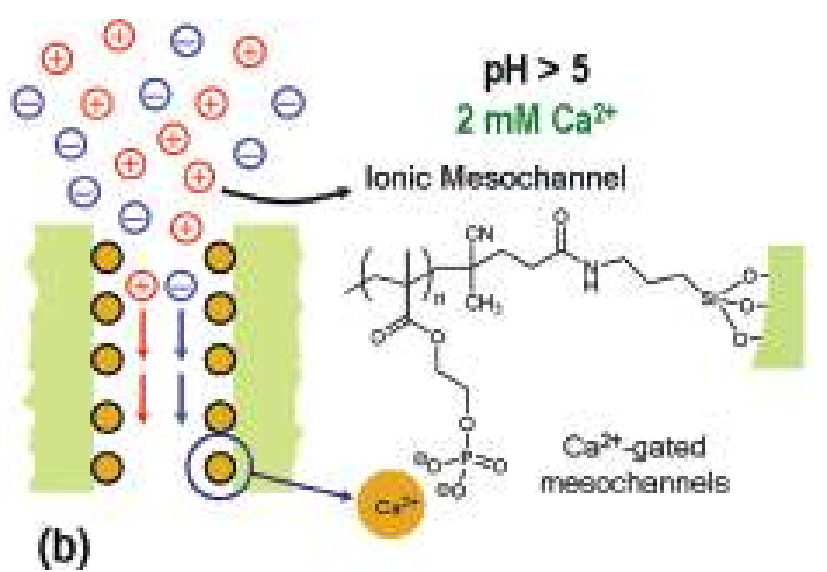

Figure 8. Schematic depiction of the ionic transport processes taking place in the PMEP-modified mesopores at $\mathrm{pH}>5$ : $(\mathrm{a})$ no added $\mathrm{Ca}{ }^{2+}$ ions, permselective transport of cations; (b) $2 \mathrm{mM} \mathrm{Ca}{ }^{2+}$, chelation-induced formation of ionic mesochannels (no exclusion of ionic species). 

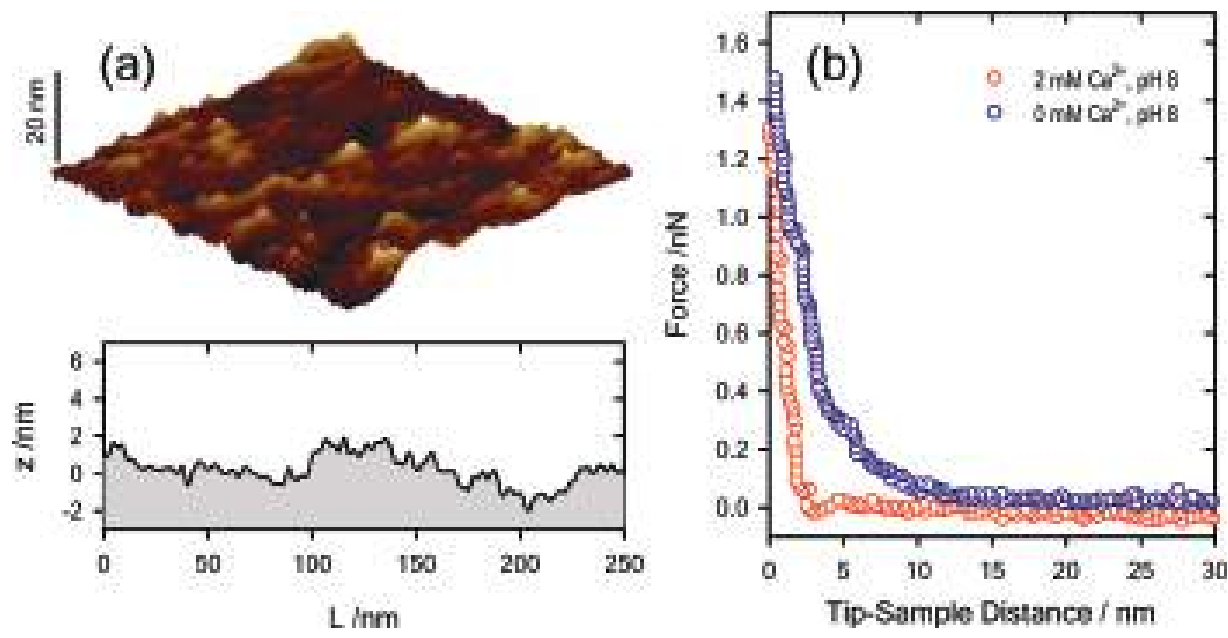

Figure 9. (a) In situ AFM three-dimensional topography image and respective cross section of PMEP-modified mesoporous film obtained in the presence of $2 \mathrm{mM} \mathrm{CaCl}_{2}+0.1 \mathrm{M} \mathrm{KCl}$ (tapping mode; maximum $z$-scale: $20 \mathrm{~nm}$; scan size: $250 \mathrm{~nm} \times 250 \mathrm{~nm}$ ). (b) Force-distance approach plots of a PMEP-modified mesoporous siica film at $\mathrm{pH} 8$ in the presence $\left(2 \mathrm{mM} \mathrm{CaCl}_{2}+0.1 \mathrm{M} \mathrm{KCl}\right)$ and in the absence of $\mathrm{Ca}^{2+}$ ions (electrolyte: $0.1 \mathrm{M}$ $\mathrm{KCl})$.
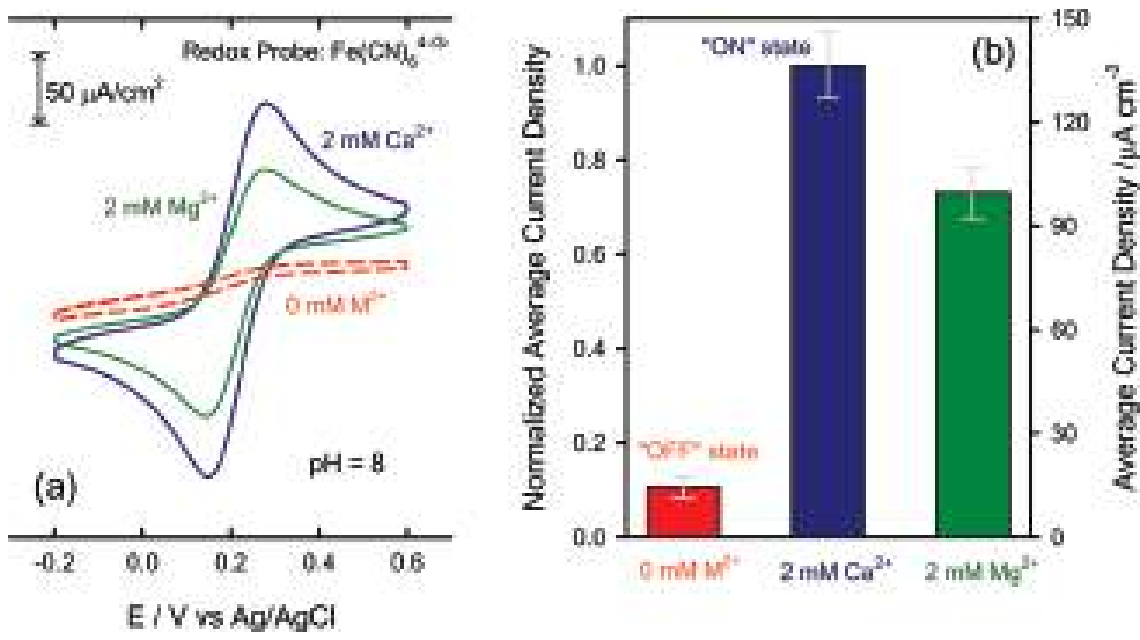

Figure 10. (a) CV studies of molecular transport through PMEP-modified mesoporous thin films in the absence of divalent cations (dotted red trace) and in the presence of $\mathrm{Ca}^{2+}\left(2 \mathrm{mM} \mathrm{CaCl}_{2}+\right.$ supporting electrolyte $)$ or $\mathrm{Mg}^{2+}(2 \mathrm{mM} \mathrm{MgCl}$ + supporting electrolyte). The voltammetric response in the absence of divalent cations has been included as a comparative reference system. Scan rate: $200 \mathrm{mV} / \mathrm{s}$. Supporting electrolyte: $1 \mathrm{mM}$ $\mathrm{Fe}(\mathrm{CN})_{6}{ }^{3-}$ (redox probe) $+0.1 \mathrm{M} \mathrm{KCl}(\mathrm{pH} 8)$. (b) Histograms showing (normalized and average) variations in electrochemical current densities arising from the influence of $\mathrm{Ca}^{2+}$ and $\mathrm{Mg}^{2+}$ cations on the molecular transport of redox probes through the mesopores.

AFM imaging and force-distance plots of the outer PMEPmodified mesoporous surface also revealed significant changes upon chelation with $\mathrm{Ca}^{2+}$ ions (Figure 9). The AFM topography image (Figure 9a) illustrates the collapsed morphology of the outer MEP film when compared with the fully extended PMEP brushes at $\mathrm{pH} 8$ (Figure $5 \mathrm{~b}$ ). The forcedistance plot of the PMEP-modified mesoporous film obtained at $\mathrm{pH} 8$ and $2 \mathrm{mM} \mathrm{Ca}^{2+}$ solution confirms the considerable collapsed state due to the absence of the steric compressive interaction of the probe with the sample (Figure $9 b$ ).

Referring back to the electrochemical experiments, it is worth highlighting that the sequence of voltammograms displayed in Figure 6 eloquently illustrates that $\mathrm{Ca}^{2+}$ ions promote the opening of the ionic mesochannels regardless of any $\mathrm{pH}$ condition. However, this is not the case in solutions of different $\mathrm{pH}$ but in the absence of $\mathrm{Ca}^{2+}$. The electrochemical currents of the cyclic voltammograms reveals that the magnitude of the ionic transport of $\mathrm{Fe}\left(\mathrm{CN}_{6}\right)^{3-}$ probes in the presence of $\mathrm{Ca}^{2+}$ is similar to that measured in fully neutralized mesochannels. This implies that the chelation of MEP units with $\mathrm{Ca}^{2+}$ controls the gating properties of the hybrid assembly and switches the permselective pores into ionic mesochannels. For instance, the rinsing of $\mathrm{Ca}^{2+}$-chelated interfacial architectures with a dilute solution of ethylenediaminetetraacetic acid (EDTA) partially removes the calcium ions bound to the phosphate-bearing polymer brush. The removal of $\mathrm{Ca}^{2+}$ ions translates into a significant decrease in the electrochemical signal corresponding to the diffusion of $\mathrm{Fe}\left(\mathrm{CN}_{6}\right)^{3-}$ ions due to the reappearance of $\mathrm{MEP}^{2-}$ monomer units in the mesochannel (see Figure S5 in the Supporting Information file). It worth mentioning that a similar effect is also observed upon removal of $\mathrm{Ca}^{2+}$ ions from the mesochannel by extensive rinsing with supporting electrolyte $(0.1 \mathrm{M} \mathrm{KCl})$.

Finally, we compared the responsiveness of the ionic mesochannels and the versatility of $\mathrm{Ca}^{2+}$ as a chemical trigger of phosphate-decorated nanogates with a similar PMEP- 
modified assembly in the presence of $\mathrm{Mg}^{2+}$ (which represents another important example of a biologically relevant divalent cation). Ionic transport of $\mathrm{Fe}\left(\mathrm{CN}_{6}\right)^{3-}$ ions measured by $\mathrm{CV}$ indicates that $\mathrm{Mg}^{2+}$ ions also promote the opening of the ionic mesochannels; however, the chemical stimulus (chelation) of $\mathrm{Mg}^{2+}$ is less efficient than that of $\mathrm{Ca}^{2+}$ for triggering the transport of anions provided that electrochemical currents of $\mathrm{Fe}\left(\mathrm{CN}_{6}\right)^{3-}$ species are 78 and $116 \mu \mathrm{A} / \mathrm{cm}^{2}$, respectively (Figure 10). A similar effect was observed by Takehara and coworkers in experiments regarding the ion-gate response of dipeptide monolayers formed on gold electrodes. ${ }^{47}$ According to these authors, differences in gating performance between $\mathrm{Ca}^{2+}$ and $\mathrm{Mg}^{2+}$ could be ascribed to differences in water exchange rate between the inner hydration shells $\left(\mathrm{Mg}^{2+}<\right.$ $\mathrm{Ca}^{2+}$. Under conditions of restricted conformational change, as in the case of pore-grafted PMEP brushes, the slower dehydration of the inner shell may bring about the lower coordination stability of the $\mathrm{M}^{2+}$-phosphate chelate. It should be noted in this context that the slower dehydration of $\mathrm{Mg}^{2+}$ inner shell is believed to hinder the permeation of this ion through the glutamate receptor channel, while $\mathrm{Ca}^{2+}$ is known to permeate through this channel. ${ }^{42}$

\section{CONCLUSIONS}

The design of hybrid interfaces based on the use of mesoporous thin films incorporating polymer brushes as versatile functional units offers major opportunities for controlling molecular transport through interfaces. The exploratory work reported here provides considerable encouragement that the idea of merging concepts and tools from self-assembly, "soft chemistry", and polymer science to construct multifunctional materials in close resemblance to biological examples is not only feasible but potentially extremely fruitful. The approach offers the possibility of designing advanced functional thin films, but we envision that this strategy could be extended to even more complex hierarchical devices, e.g.: templated aligned mesopores within channels ${ }^{48}$ or selectively functionalized multilayers. ${ }^{49}$ The modification of mesoporous silica thin films with phosphate-bearing polyprotic polymer brushes led to a hybrid interfacial architecture displaying arrays of stimuliresponsive mesochannels whose ionic transport properties can be finely tuned in the presence of protons and calcium ions. In the case of protons, the electrostatic characteristics of the thermodynamically controlled environments arising from the multiple protonation states of phosphate groups are responsible for tuning the ionic transport of anionic and cationic redox probes across the mesoporous framework over a wide range of $\mathrm{pH}$. Increasing $\mathrm{pH}$ from 4 to 8 led to a significant increase in (anion) permselectivity and (cation) preconcentration, thus reflecting the ability of the PMEP brush-modified mesopores to act as a selective "electrostatic nanovalve" precluding and boosting the anionic and cationic transport, respectively. On the other hand, the complexation/chelation of phosphate groups with $\mathrm{Ca}^{2+}$ ions also allowed the generation of gatelike hybrid ensembles. Our results demonstrate that the hybrid interface at $\mathrm{pH} 8$ reversibly switches from low to high anionic conductance states depending on the formation of stable $\mathrm{Ca}^{2+}-$ phosphate complexes in the mesochannels. Hence, at high $\mathrm{pH}$ values, MEP-modified pores are strongly permselective precluding the transport of anionic probes; however, once $\mathrm{Ca}^{2+}$ are bound to the monomer units, the ionic mesochannel reaches the open state. We consider that this work represents an important thrust in the direction of innovative design of new hybrid mesoporous interfaces as well as illustrates the potential and versatility of polyprotic $\mathrm{pH}$-responsive macromolecular building blocks as key enablers to achieve bioinspired integrated functional gate-like ensembles mimicking the transport properties and gating functions of specific biological channels.

\section{ASSOCIATED CONTENT}

S Supporting Information

Additional figures corresponding to the in-depth characterization of the experimental systems. This material is available free of charge via the Internet at http://pubs.acs.org.

\section{AUTHOR INFORMATION}

\section{Corresponding Author}

*(O.A.) E-mail: azzaroni@inifta.unlp.edu.ar; Homepage: http://softmatter.quimica.unlp.edu.ar. (G.J.A.A.S.-I.) E-mail: gsoler@cnea.gov.ar; Homepage: http://www.qi.fcen.uba.ar/ personales/soler-illia.htm.

\section{Notes}

The authors declare no competing financial interest.

\section{ACKNOWLEDGMENTS}

We gratefully acknowledge financial support from Agencia Nacional de Promoción Cientifica y Tecnológica (ANPCyT) (PICT 34518 and 1848, PAE 2004 22711, PICT 2010-457, and PICT-PRH 163/08), Centro Interdisciplinario de Nanociencia y Nanotecnología (CINN, PAE 2006 37063, projects PRH 2007-74, PIDRI no. 74 and PME 00038), Fundación Petruzza, Gabbos (DG-017), Max-Planck-Gesellschaft (Max Planck Partner Group - MPIP/INIFTA), Consejo Nacional de Investigaciones Científicas y Técnicas (CONICET, PIP 11220100100186), Alexander von Humbolt Stiftung, Laboratório Nacional de Luz Śincrotron (LNLS) (XRD2-11639/ 10736; SXS-11642), and Universidad de Buenos Aires (UBACYT 2010-2012, Grant No.: 20020090100164). A.B. and C.D. also acknowledge ANPCyT and CONICET, respectively, for a postdoctoral fellowship. L.I.P., M.C., G.J.A.A.S.-I., and O.A. are CONICET fellows.

\section{ADDITIONAL NOTE}

Originally submitted for the "Bioinspired Assemblies and Interfaces" Special Issue, published as the January 31, 2012 issue of Langmuir (Vol. 28, No. 4).

\section{REFERENCES}

(1) (A) Fu, Q.; Rao, G. V. R.; Ista, L. K.; Wu, Y.; Andrzejewski, B. P.; Sklar, L. A.; Ward, T. L.; López, G. P. Adv. Mater. 2003, 15, 1262. (b) Park, M.-K.; Deng, S.; Advincula, R. C. J. Am. Chem. Soc. 2004, 126, 13723. (c) Fu, Q.; Rama Rao, G. V.; Ward, T. L.; Lu, Y.; López, G. P. Langmuir 2007, 23, 170. (d) Tam, T. K.; Pita, M.; Motornov, M.; Tokarev, I.; Minko, S.; Katz, E. Adv. Mater. 2010, 22, 1863.

(2) (a) Aguilella, V.; Kontturi, K.; Murtomaki, L.; Ramírez, P. J. Controlled Release 1994, 32, 249. (b) Rojanasakul, Y.; Robinson, J. R. Int. J. Pharm. 1989, 55, 237.

(3) (a) Brunsen, A.; Cui, J.; Ceolín, M.; del Campo, A.; Soler-Illia, G. J. A. A.; Azzaroni, O. Chem. Commun. 2012, 48, 1422-1424. (b) Aznar, E.; Marcos, M. A.; Martínez-Máñez, R.; Sancenón, F.; Soto, J.; Amorós, P.; Guillem, C. J. Am. Chem. Soc. 2009, 131, 6833. (c) Martínez-Máñez, R.; Sancenón, F.; Hecht, M.; Biyikal, M.; Rurack, K. Anal. Bioanal. Chem. 2011, 399, 55. (d) Aznar, E.; Casasús, R; García-Acosta, B.; Marcos, M. D.; Martínez-Máñez, R.; Sancenón, F.; Soto, J.; Amorós, P. Adv. Mater. 2007, 19, 2228. (e) Liu, N.; Dunphy, D. R.; Atanassov, P.; Bunge, S. D.; Chen, Z.; López, G. P.; Boyle, T. J.; 
Brinker, C. J. Nano Lett. 2004, 4, 551. (f) Angelos, S.; Yang, Y.-W.; Khashab, N. M.; Stoddart, J. F.; Zink, J. I. J. Am. Chem. Soc. 2009, 131, 11344.

(4) (a) Ito, Y.; Inaba, M.; Chung, D.-J.; Imanishi, Y. Macromolecules 1992, 25, 7313-7316. (b) Park, Y. S.; Ito, Y.; Imanishi, Y. Chem. Mater. 1997, 9, 2755-2758. (c) Ito, Y.; Ochiai, Y.; Park, Y. S.; Imanishi, Y. J. Am. Chem. Soc. 1997, 119, 1619-1623.

(5) Fan, R.; Huh, S.; Yan, R.; Arnold, J.; Yang, P. Nat. Mater. 2008, 7, 303-307.

(6) (a) Jiang, Y.; Lee, A.; Chen, J.; Cadene, M.; Chait, B. T.; MacKinnon, R. Nature 2002, 417, 515. (b) Jiang, Y.; Lee, A.; Chen, J.; Cadene, M.; Chait, B. T.; MacKinnon, R. Nature 2002, 417, 523.

(7) Hille, B. Ion Channels of Excitable Membranes, 3rd ed.; Sinauer Associates: Sunderland U.K., 2011.

(8) (a) The Supramolecular Chemistry of Organic-Inorganic Hybrid Materials; Rurack, K., Martínez-Máñez, R., Eds.; John Wiley \& Sons: Hoboken, 2010. (b) Descalzo, A. B.; Martínez-Máñez, R.; Sancenón, F.; Hoffmann, K.; Rurack, K. Angew. Chem., Int. Ed. 2006, 45, 5924.

(9) Biological Membrane Ion Channels: Dynamics, Structure, and Applications; Chung, S.-H., Anderson, O. S., Krishnamurthy, V. V., Eds.; Springer-Verlag: Heidelberg, 2010.

(10) Ion Channels: From Structure to Function; Kew, J., Davies, C., Eds.; Oxford University Press: Oxford, 2010.

(11) Soler-Illia, G. J. A. A.; Innocenzi, P. Chem.-Eur. J. 2006, 12, 4478.

(12) (a) Barbey, R.; Lavanant, L.; Paripovic, D.; Schüwer, N.; Sugnaux, C.; Tugulu, S.; Klok, H.-A. Chem. Rev. 2009, 109, 5437. (b) Advincula, R. C., Brittain, W. J., Caster, K. C., Rühe, J., Eds.; WileyVCH: Weinheim, Germany, 2004. (c) Azzaroni, O.; Brown, A. A.; Huck, W. T. S. Angew. Chem., Int. Ed. 2006, 45, 1770. (d) Advincula, R. C. In Surface- Initiated Polymerization I; Jordan, R., Ed.; SpringerVerlag: Heidelberg, 2006; p 107.

(13) Calvo, A.; Yameen, B.; Williams, F. J.; Soler-Illia, G. J. A. A.; Azzaroni, O. J. Am. Chem. Soc. 2009, 131, 10866.

(14) Soler-Illia, G. J. A. A.; Azzaroni, O. Chem. Soc. Rev. 2011, 40, 1107.

(15) (a) Casasús, R.; Marcos, M. D.; Martínez-Máñez, R.; Ros-Lis, J. V.; Soto, J.; Villaescusa, L. A.; Amorós, P.; Beltrán, D.; Guillem, C.; Latorre, J. J. Am. Chem. Soc. 2004, 126, 8612. (b) Casasús, R.; Climent, E.; Marcos, M. A.; Martínez-Máñez, R.; Sancenón, F.; Soto, J.; Amorós, P.; Cano, J.; Ruiz, E. J. Am. Chem. Soc. 2008, 130, 1903.

(16) (a) Angelatos, A. S.; Wang, Y.; Caruso, F. Langmuir 2008, 24, 4224. (b) Wang, Y.; Angelatos, A. S.; Dunstan, D. E.; Caruso, F. Macromolecules 2007, 40, 7594. (c) Wang, Y.; Caruso, F. Chem. Mater. 2006, 18, 4089. (d) Wang, Y.; Bansal, V.; Zelikin, A. N.; Caruso, F. Nano Lett. 2008, 8, 1741.

(17) Yameen, B.; Ali, M.; Neumann, R.; Ensinger, W.; Knoll, W.; Azzaroni, O. Chem. Commun. 2010, 46, 1908.

(18) Walcarius, A. Anal. Bioanal. Chem. 2010, 396, 261.

(19) Hutter, J. L.; Bechhoefer, J. Rev. Sci. Instrum. 1993, 64, 1868.

(20) Ducker, W. A.; Senden, T. J.; Pashley, R. M. Langmuir 1992, 8, 1831 .

(21) Soler-Illia, G. J. A. A.; Sanchez, C.; Lebeau, B.; Patarin, J. Chem. Rev. 2002, 102, 4093.

(22) Boissiére, C.; Grosso, D.; Lepoutre, S.; Nicole, L.; BrunetBruneau, A.; Sanchez, C. Langmuir 2005, 21, 12362.

(23) Kim, T.-W.; Ryoo, R.; Kruk, K.; Gierszal, K. P.; Jaroniec, M.; Kamiya, S.; Terasaki, O. J. Phys. Chem. B 2004, 108, 11480-11489.

(24) Brunsen, A.; Calvo, A.; Williams, F. J.; Soler-Illia, G. J. A. A.; Azzaroni, O. Langmuir 2011, 27, 4328.

(25) Calvo, A.; Yameen, Y.; Williams, F. J.; Azzaroni, O.; Soler-Illia, G. J. A. A. Chem Commun. 2009, 2553.

(26) Gibaud, A.; Hazra, S. Curr. Sci. 2000, 78, 1467.

(27) Calvo, A.; Fuertes, M. C.; Yameen, B.; Williams, F. J.; Azzaroni, O.; Soler-Illia, G. J. A. A. Langmuir 2010, 26, 5559.

(28) Dourdain, S.; Mehdi, A.; Bardeau, J. F.; Gibaud, A. Thin Solid Films 2006, 495, 205-209.

(29) (a) Pinto, L. H.; Holsinger, L. J.; Lamb, R. A. Cell 1992, 69, 517-528. (b) Kass, I.; Arkin, I. T. Structure 2005, 13, 1789-1798.
(30) (a) Okada, A.; Miura, T.; Takeuchi, H. Biochemistry 2001, 40, 6053. (b) Takeuchi, H.; Okada, A.; Miura, T. FEBS Lett. 2003, 552, 35.

(31) (a) Etienne, M.; Quach, A.; Grosso, D.; Nicole, L.; Sanchez, C.; Walcarius, A. Chem. Mater. 2007, 19, 844. (b) Fattakhova-Rohlfing, D.; Wark, M.; Rathousky, J. Chem. Mater. 2007, 19, 1640.

(32) Zhang, J.; Kirkham, J.; Robinson, C.; Wallwork, M. L.; Smith, D. A.; Marsh, A; Wong, M. Anal. Chem. 2000, 72, 1973.

(33) Zhou, F.; Huck, W. T. S. Chem. Commun. 2005, 5999.

(34) (a) Rapuano, R.; Carmona-Ribeiro, A. M. J. Colloid Interface Sci. 1997, 193, 104. (b) Mercier, P.; Savoie, R. Biospectroscopy 1997, 3, 299. (c) Murray, D. K. J. Colloid Interface Sci. 2010, 352, 163. (d) Murray, D. K.; Harrison, J. C.; Wallace, W. E. J. Colloid Interface Sci. 2005, 288, 166.

(35) For the sake of simplicity we have considered the value of the anodic peak current density as the electrochemical readout arising from the diffusion of redox probes through the mesoporous assembly.

(36) Tagliazucchi, M.; Olvera de la Cruz, M.; Szleifer, I. Proc. Natl. Acad. Sci. U.S.A. 2010, 107, 5300.

(37) To provide an illustrative example, we should consider human blood plasma that contains $143 \mathrm{mM} \mathrm{Na}^{+}, 5 \mathrm{mM} \mathrm{K}^{+}, 2.5 \mathrm{mM} \mathrm{Ca}^{+}, 1$ $\mathrm{mM} \mathrm{Mg}^{2+}, 103 \mathrm{mM} \mathrm{Cl}^{-}, 27 \mathrm{mM} \mathrm{HCO}_{3}^{-}, 1 \mathrm{mM} \mathrm{HPO}_{4}{ }^{2-}$, and $0.5 \mathrm{mM}$ $\mathrm{SO}_{4}{ }^{2-}$. Total concentration of divalent cations is significantly lower than monovalent cations.

(38) (a) Rupert, L. A. M.; Hoekstra, D.; Engberts, J. B. F. N. J. Colloid Interface Sci. 1989, 130, 271. (b) Chen, S.; Huang, K. Anal. Chem. 2000, 72, 2949. (c) Schmidt, G.; Eibl, H.; Knoll, W. J. Membr. Biol. 1982, 70, 147. (d) Knoll, W.; Apell, H.-J.; Eibl, H.; Miller, A. Eur. Biophys. J. 1986, 13, 187.

(39) Ichas, F.; Mazat, J.-P. Biochim. Biophys. Acta 1998, 1366, 33.

(40) Hartzell, C.; Putzier, I.; Arreola, J. Annu. Rev. Physiol. 2005, 67, 719.

(41) Imbert, E.; Souirti, A.; Menard, V.; Plucer, F.; Josefowicz, M.; Miconney, V. J. Appl. Polym. Sci. 1994, 52, 91.

(42) Nakashima, N.; Taguchi, T.; Takada, Y.; Fujio, K.; Kunitake, M.; Manabe, O. J. Chem. Soc., Chem. Commun. 1991, 232.

(43) Greenfield, M. A.; Hoffman, J. R.; de La Cruz, M. O.; Stupp, S. I. Langmuir 2010, 26, 3641.

(44) (a) Siwy, Z. S.; Powell, M. R.; Petrov, A.; Kalman, E.; Trautmann, C.; Eisenberg, R. S. Nano Lett. 2006, 6, 1729. (b) Powell, M. R.; Sullivan, M.; Vlassiouk, I.; Constantin, D.; Sudre, O.; Martens, C. C.; Eisenberg, R. S.; Siwy, Z. S. Nat. Nanotechnol. 2008, 3, 51.

(45) Kühnle, R. I.; Börner, H. G. Angew. Chem., Int. Ed. 2011, 50, 4499.

(46) Kühnle, R. I.; Gebauer, D.; Börner, H. G. Soft Matter 2011, DOI: $10.1039 / \mathrm{clsm} 05625 \mathrm{e}$.

(47) Takehara, K.; Aihara, M.; Miura, Y; Tanaka, F. Bioelectrochem. Bioenerg. 1996, 39, 135.

(48) (a) Yamauchi, Y.; Suzuki, N.; Kimura, T. Chem. Commun. 2009, 5689. (b) Suzuki, N.; Kimura, T.; Yamauchi, Y. J. Mater. Chem. 2010, 10, 5294.

(49) (a) Angelomé, P. C.; Fuertes, M. C.; Soler-Illia, G. J. A. A. Adv. Mater. 2006, 18, 2397. (b) Fuertes, M. C.; López-Alcaraz, F. J.; Marchi, M. C.; Troiani, H.; Luca, V.; Míguez, H.; Soler-Illia, G. J. A. A. Adv. Funct. Mater. 2007, 17, 1247. (c) Soler-Illia, G. J. A. A.; Angelomé, P. C.; Fuertes, M. C.; Calvo, A.; Wolosiuk, A.; Zelcer, A; Bellino, M. G.; Martínez, E. D. J. Sol-Gel Sci. Technol. 2011, 57, 299. 